\title{
Kinetics of Radical Copolymerization between $\alpha$-Methylstyrene and Methyl Methacrylate
}

\author{
Katsukiyo ITO and Kazuo KoDAIRA \\ Government Industrial Research Institute, \\ Nagoya, Kita-ku, Nagoya 462, Japan
}

(Received March 26, 1986)

\begin{abstract}
The theoretical treatment of copolymerization with propagation and depopagation is presented in order to estimate $r_{1}, r_{2}$, and $K_{11}$ (the equilibrium constant for propagation and depropagation) in the copolymerization of $\alpha$-methylstyrene ( $\left.\alpha \mathrm{MSt}: M_{1}\right)$ and methyl methacrylate (MMA: $M_{2}$ ). The values of $r_{1}, r_{2}$, and $K_{11}$ are found to be $0.48,0.47$, and 5.0 , respectively. The termination rate constant in the copolymerization is estimated to be $3.3 \times 10^{7}$ regardless of monomer feed composition. This means that a $\phi$-factor proposed by Walling is equal to unity.

KEY WORDS Copolymerization / Propagation / Depropagation / $\alpha$ Methylstyrene / Methyl Methacrylate / Values of $r_{1}, r_{2} /$ Equilibrium Constant / Termination Rate /
\end{abstract}

In order to treat cross termination in radical copolymerization, Walling ${ }^{1}$ used a $\phi$-factor as $\phi=k_{\mathrm{t} 12} /\left(k_{\mathrm{t} 11} k_{\mathrm{t} 12}\right)^{1 / 2}$. In the copolymerizations of methylmethacrylate (MMA) with vinylacetate $^{2}$ and styrene with $\alpha$-methylmethacrylate $(\alpha \mathrm{MSt}),{ }^{3} \phi$ could be set up unity, since the rates are diffusion-controlled. ${ }^{4}$ On the other hand, $\phi$ was larger than 10 in the copolymerization of styrene with some methacrylates. $^{1,5-7}$ Such larger values have been ascribed to polar effects which favor cross termination. Russo et al. $^{7}$ proposed a model based on the steric effect in terms of the penultimate unit. In the preceeding paper, ${ }^{4}$ we showed that the Russo model could not be applied to the data on the copolymerization of dodecylmethacrylate (DMA) and MMA, in spite of the statement ${ }^{8}$ that it is the best model. To examine the Russo model in more detatil, it is suitable to choose a monomer of which the steric hindrance of $\alpha$-carbon atom is larger than that of styrene. Thus, in this article, a copolymerization system between $\alpha \mathrm{MSt}$ and MMA is chosen. However, the kinetics of this system are more complex than those of the above, because depropagation cannot be neglected in the former but are negligible in the others. Thus, the kinetics for the copolymerization with propagation and depropagation are treated precisely, to estimate $r_{1}, r_{2}$, and $K_{11}$. Using these values, the termination rate is calculated and discussed.

\section{THEORY}

Polymerization scheme:

$$
\begin{aligned}
& \sim \mathrm{M}_{1}^{\bullet}+\mathrm{M}_{1} \rightleftarrows \sim \mathrm{M}_{1} \mathrm{M}_{1}^{\bullet} \\
& \sim \mathrm{M}_{1}^{\bullet}+\mathrm{M}_{2} \rightarrow \sim \mathrm{M}_{1} \mathrm{M}_{2}^{\bullet} \\
& \sim \mathrm{M}_{2}^{\bullet}+\mathrm{M}_{1} \rightarrow \sim \mathrm{M}_{2} \mathrm{M}_{1}^{\bullet} \\
& \sim \mathrm{M}_{2}^{\bullet}+\mathrm{M}_{2} \rightarrow \sim \mathrm{M}_{2} \mathrm{M}_{2}^{\bullet}
\end{aligned}
$$

Wittmer ${ }^{10}$ derived the following ratios:

$$
F_{2}=\frac{\left[\mathrm{M}_{1}\right]\left[\mathrm{M}_{2}\right]+r_{2}\left[\mathrm{M}_{2}\right]^{2}}{\left(r_{1}\left[\mathrm{M}_{1}\right]^{2}+2\left[\mathrm{M}_{1}\right]\left[\mathrm{M}_{2}\right]+r_{2}\left[\mathrm{M}_{2}\right]^{2}\right)\left(1-K_{\mathrm{p}}\right)}
$$




$$
\begin{gathered}
K_{\mathrm{p}}=\frac{r_{1} K_{11} \sigma\left[\mathrm{M}_{1}\right]}{r_{1}\left[\mathrm{M}_{1}\right]^{2}+2\left[\mathrm{M}_{1}\right]\left[\mathrm{M}_{2}\right]+r_{2}\left[\mathrm{M}_{2}\right]^{2}} \\
\sigma=\frac{r_{1}\left[\mathrm{M}_{1}\right]+\left[\mathrm{M}_{2}\right]+r_{1} K_{11}-\left[\left(r_{1}\left[\mathrm{M}_{1}\right]+\left[\mathrm{M}_{2}\right]+r_{1} K_{11}\right)^{2}-4 r_{1}{ }^{2} K_{11}\left[\mathrm{M}_{1}\right]\right]^{1 / 2}}{2 r_{1} K_{11}}
\end{gathered}
$$

The polymerization rate is written as:

$$
\begin{aligned}
& R_{\mathrm{p}}=-\frac{\mathrm{d}\left[\mathrm{M}_{1}\right]+\mathrm{d}\left[\mathrm{M}_{2}\right]}{\mathrm{d} t} \\
& =\left(k_{11}\left[\mathrm{M}_{1}\right]+k_{12}\left[\mathrm{M}_{2}\right]\right)\left[\mathrm{N}^{1}\right]+\left(k_{21}\left[\mathrm{M}_{1}\right]+k_{22}\left[\mathrm{M}_{2}\right]\right)\left[\mathrm{N}^{2}\right]-k_{11} \sigma\left[\mathrm{N}^{2}\right] \\
& =k_{\mathrm{p}}\left(1-K_{\mathrm{p}}\right)\left(2 f k_{\mathrm{d}}[\mathrm{C}] / k_{t}\right)^{1 / 2} \\
& \qquad k_{\mathrm{p}}=\frac{k_{11} k_{22}\left(r_{1}\left[\mathrm{M}_{1}\right]^{2}+2\left[\mathrm{M}_{1}\right]\left[\mathrm{M}_{2}\right]+r_{2}\left[\mathrm{M}_{2}\right]^{2}\right)}{r_{1} k_{22}\left[\mathrm{M}_{1}\right]+r_{2} k_{11}\left[\mathrm{M}_{2}\right]} \\
& \mathrm{d}\left[\mathrm{N}_{n}\right] / \mathrm{d} t=\left(k_{11}\left[\mathrm{M}_{1}\right]+k_{12}\left[\mathrm{M}_{2}\right]\right)\left(\left[\mathrm{N}_{n-1}^{1}\right]-\left[\mathrm{N}_{n}^{1}\right]\right)+\left(k_{21}\left[\mathrm{M}_{1}\right]+k_{22}\left[\mathrm{M}_{2}\right]\right)\left(\left[\mathrm{N}_{n-1}{ }^{2}\right]-\left[\mathrm{N}_{2}^{2}\right]\right) \\
& \quad+k_{\overline{11}} \sigma\left[\mathrm{N}_{n+1}\right]-\left(k_{r 11}\left[\mathrm{M}_{1}\right]+k_{r 12}\left[\mathrm{M}_{2}\right]\right)\left[\mathrm{N}_{n}{ }^{1}\right]-\left(k_{r 12}\left[\mathrm{M}_{1}\right]+k_{r 22}\left[\mathrm{M}_{2}\right]\right)\left[\mathrm{N}_{n}{ }^{2}\right]=0
\end{aligned}
$$

This is rewritten as:

$$
\begin{aligned}
& \mathrm{d}\left[\mathrm{N}_{n}\right] / k_{\mathrm{p}} \mathrm{dt}=\left(\left[\mathrm{N}_{n-1}\right]-\left[\mathrm{N}_{n}\right]\right)+K_{\mathrm{p}}\left[\mathrm{N}_{n+1}\right]-2 f k_{\mathrm{d}}[\mathrm{C}]\left[\mathrm{N}_{n}\right] / R_{\mathrm{p}}-C_{\mathrm{tr}}\left[\mathrm{N}_{n}\right]=0 \\
& {\left[\mathrm{~N}_{n-1}\right] \simeq\left[\mathrm{N}_{n}\right]-\mathrm{d}\left[\mathrm{N}_{n}\right] / \mathrm{d} t} \\
& {\left[\mathrm{~N}_{n+1}\right] \simeq\left[\mathrm{N}_{n}\right]+\mathrm{d}\left[\mathrm{N}_{n}\right] / \mathrm{d} t} \\
& \mathrm{~d}\left[\mathrm{~N}_{n}\right] / \mathrm{d} n+\beta\left[\mathrm{N}_{n}\right] \simeq 0 \\
& \beta=2 f k_{\mathrm{d}}[\mathrm{C}] / R_{\mathrm{p}}+\left(C_{\mathrm{tr}}-K_{\mathrm{p}}\right) /\left(1-K_{\mathrm{p}}\right)
\end{aligned}
$$$$
C_{t r}=\frac{\left.r_{1} C_{11: 11}\left[\mathrm{M}_{1}\right]^{2}+\left(r_{1} C_{12: 11}+r_{2} C_{21: 22}\right)\left[\mathrm{M}_{1}\right]\left[\mathrm{M}_{2}\right]+r_{2} C_{22: 22}\right)\left[\mathrm{M}_{2}\right]^{2}}{r_{1}\left[\mathrm{M}_{1}\right]^{2}+2\left[\mathrm{M}_{1}\right]\left[\mathrm{M}_{2}\right]+r_{2}\left[\mathrm{M}_{2}\right]^{2}}
$$

The solution is:

$$
\left[\mathrm{N}_{n}\right] /[\mathrm{N}]=\beta \exp \left(-\beta_{n}\right)
$$

Following the usual manner, the weightaverage degree of polymerization is written as eq 18 , when disproportionation predominates.

$$
X_{w}\left(=2 X_{n}\right)=2 / \beta
$$

A linear relationship between $2 / X_{w}$ and $[\mathrm{C}] / R_{\mathrm{p}}$ is given by:

$$
2 / X_{w}=\left(C_{\mathrm{tr}}-K_{\mathrm{p}}\right) /\left(1-K_{\mathrm{p}}\right)+2 f k_{\mathrm{d}}\left([\mathrm{C}] / R_{\mathrm{p}}\right)
$$

\section{EXPERIMENTAL}

Commercial $\alpha$ MSt and MMA were purified by a similar method as described before. ${ }^{6}$ Azophenylethane (APE) was prepared by the method described previously. ${ }^{9}$

The monomers and APE in the ampoule were degassed at a vacuum of about $10^{-3}$ $\mathrm{mmHg}$. The ampoule was maintained at $60.0 \pm 0.05^{\circ} \mathrm{C}$ for a given polymerization time. The polymer was precipitated by adding methanol, and purified using tetrahydrofuran and methanol when $\left[\mathrm{M}_{1}\right]$ was less than 2.98 mol dm ${ }^{-3}$. When larger than 2.98 , the weight loss on the purification of the polymers was not negligible and, then, the conversion was estimated by liquid chromatography, using a Jasco TRI ROTOR high pressure liquid chromatogram with refractive index detector (RI) and ultraviolet one (UV). The monomer composition in the copolymer was es- 
timated by elemental analysis and the above liquid chromatography. The later method is more suitable when $1 \gg F_{1}$, since ratio (= 0.506 ) of RI of polyMMA to RI of poly $\alpha \mathrm{MSt}$ is exceedingly larger than the ratio $(=0.027)$ of absorptivity of polyMMA to that of poly$\alpha \mathrm{MSt}$ at $254 \mathrm{~nm}$ in UV. The weight-average degree of polymerization was measured by gel permeation chromatography, using a Toyo Soda HLC-802A with low angle light scattering detector. All units in terms of concentrations and rates are shown in $\mathrm{mol}, \mathrm{dm}^{3}$, and $\mathrm{s}$.

\section{RESULTS AND DISCUSSION}

Estimations of $r_{1}, r_{2}$, and $K_{11}$

Designating as $F_{2}=G\left(\left[\mathrm{M}_{2}\right]: r_{1}, r_{2}, \mathrm{~K}_{11}\right)$, a modification of Tidwell and Mortimer's meth$\mathrm{od}^{11}$ along eq 6 was applied to the data in Table I and all Wittmer's data. ${ }^{10}$ However, $r_{1}$, $r_{2}$, and $K_{11}$ did not converge to the respective most probable values. Fortunately, the $r_{1}$ and $r_{2}$ converged to the respective most probable values at a given value of $K_{11}$. In this case, $F_{2}$ is written as $G\left(\left[\mathrm{M}_{2}\right]: r_{1}, r_{2}\right)$ where $K_{11}=$ constant. The values of $r_{1}$ and $r_{2}$ at the given value of $K_{11}$ are shown in Figure 1, where the data in Table I are used. Wittmer estimated the $r_{1}$ and $r_{2}$ values, using $K_{11}=7.1$ in anionic polymerization. In the present paper, we can obtain the value of $K_{11}$ without the use of the results in the anionic polymerization. When $\left[\mathrm{M}_{1}\right] \ll\left[\mathrm{M}_{2}\right]$, eq 6 is reduced to:

$$
\begin{aligned}
& \mathrm{d}\left[\mathrm{M}_{1}\right] / \mathrm{d}\left[\mathrm{M}_{2}\right]=\left(1 / r_{2}\right)\left(\left[\mathrm{M}_{1}\right] /\left[\mathrm{M}_{2}\right]\right) \\
& \quad+\left(r_{1} / r_{2}-1 / r_{2}{ }^{2}-r_{1}{ }^{2} K_{11} / r_{2}\right)\left(\left[\mathrm{M}_{1}\right] /\left[\mathrm{M}_{2}\right]\right)^{2}+\ldots \\
& \simeq\left(1 / r_{2}\right)\left(\left[\mathrm{M}_{1}\right] /\left[\mathrm{M}_{2}\right]\right)
\end{aligned}
$$

A line based on eq 20 is obtained when $\left[\mathrm{M}_{1}\right] \leq 1.49$ (Figure 2). From the slope of the line, $r_{2}$ is found to be 0.47 . Using this value, the curves in Figure 2 give $r_{1}=0.48$ and $K_{11}=5.0$. The $f_{2}-F_{2}$ curve made using the above values fits well the experimental data (Figure 3). In the following section, the co-

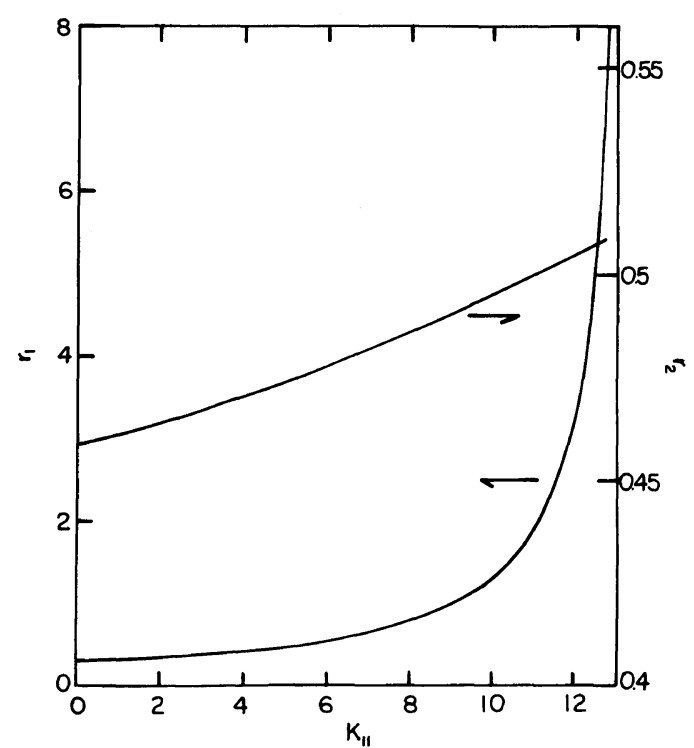

Figure 1. Relationship between $r_{1}$ and $r_{2}$ at given $K_{11}$, calculated using the data in Table $\mathrm{I}$.

Table I. The monomer coposition in copolymers $\left(\left[\mathrm{M}_{1}\right]: \alpha-\mathrm{MSt},\left[\mathrm{M}_{2}\right]\right.$ : MMA)

\begin{tabular}{llll}
\hline \multicolumn{1}{c}{$\left[\mathrm{M}_{1}\right]$} & {$\left[\mathrm{M}_{2}\right]$} & $\mathrm{d}\left[\mathrm{M}_{1}\right] / \mathrm{d}\left(\left[\mathrm{M}_{1}\right]+\left[\mathrm{M}_{2}\right]\right)$ \\
\hline 0.0375 & 8.75 & $0.99107^{\mathrm{a}}$ & \\
0.0740 & 8.70 & $0.9824^{\mathrm{a}}$ & \\
0.120 & 8.65 & $0.9728^{\mathrm{a}}$ & \\
0.149 & 8.62 & $0.9681^{\mathrm{a}}$ & \\
0.373 & 8.35 & $0.9416^{\mathrm{a}}$ & $0.940^{\mathrm{b}}$ \\
0.746 & 7.89 & $0.859^{\mathrm{a}}$ & $0.862^{\mathrm{b}}$ \\
1.491 & 7.00 & $0.741^{\mathrm{a}}$ & $0.725^{\mathrm{b}}$ \\
2.24 & 6.09 & $0.670^{\mathrm{a}}$ & $0.638^{\mathrm{b}}$ \\
2.98 & 5.20 & $0.621^{\mathrm{a}}$ & $0.601^{\mathrm{b}}$ \\
3.39 & 4.47 & & $0.518^{\mathrm{b}}$ \\
5.97 & 1.59 & & $0.340^{\mathrm{b}}$ \\
\hline
\end{tabular}

${ }^{a}$ By RI and UV.

b By elemental analysis.

polymerization rate is discussed on the basis of $r_{1}=0.48, r_{2}=0.47$, and $K_{11}=5.0$.

\section{Copolymerization Rate}

Because of $X_{w} / X_{n} \simeq 2$ (Table II), disproportionation predominates ${ }^{12}$ and eq 19 may be used. The values of $2 f k_{\mathrm{d}}$ and $k_{t} / k_{\mathrm{p}}{ }^{2}$ are found to be $3.36 \times 10^{-7}$ (APE) and 70.3 at $60^{\circ} \mathrm{C}$ by the introduction of the values obtained in the homopolymerization of MMA 


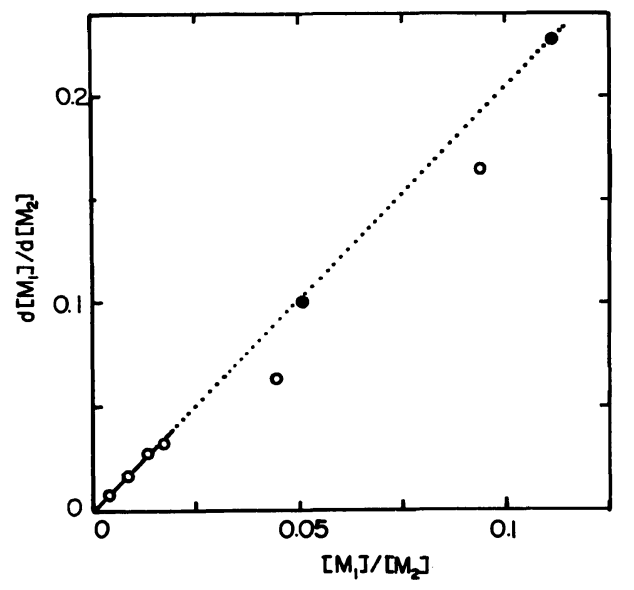

Figure 2. Estimation of $r_{2}$ when $\left[\mathrm{M}_{1}\right] \ll\left[\mathrm{M}_{2}\right](O$, the data in Table I; $\mathbf{O}$, Wittmer's data ${ }^{10}$ ).

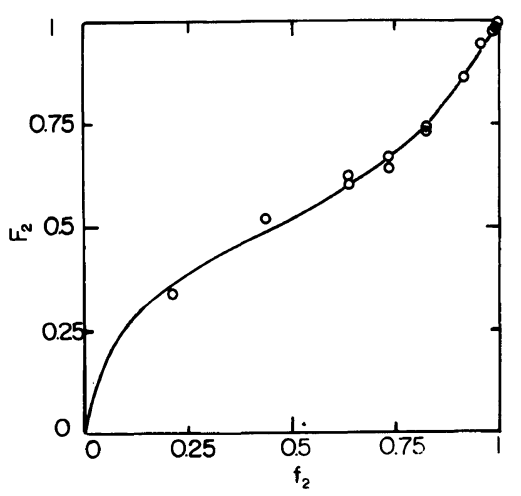

Figure 3. Copolymerization curve $(O$, experimental; $\longrightarrow$, calculated when $r_{1}=0.48, r^{2}=0.47$, and $K_{11}=5.0$.

Table II. Kinetic data

\begin{tabular}{lllccr}
\hline $1000\left[\mathrm{C}_{1}\right]$ & {$\left[\mathrm{M}_{1}\right]$} & {$\left[\mathrm{M}_{2}\right]$} & $10^{6} R_{\mathrm{p}}$ & $X_{n}$ & $X_{w}$ \\
\hline 0.20 & 5.97 & 1.59 & 1.20 & & \\
0.20 & 3.39 & 4.47 & 2.41 & & \\
0.20 & 2.98 & 5.26 & 3.98 & & \\
0.20 & 2.24 & 6.09 & 8.73 & & 235 \\
0.10 & 2.27 & 6.21 & 6.56 & 160 & 332 \\
0.050 & 2.29 & 6.26 & 5.14 & 220 & 457 \\
0.025 & 2.30 & 6.29 & 4.04 & 350 & 708 \\
0.0125 & 2.30 & 6.30 & 2.84 & 480 & 1000 \\
0.20 & 1.491 & 7.00 & 9.00 & 400 & 780 \\
0.20 & 0.746 & 7.89 & 13.0 & 500 & 1059 \\
0.20 & 0.373 & 8.35 & 26.0 & & \\
0.20 & 0.149 & 8.62 & 48.0 & & \\
0.20 & 0.0740 & 8.70 & 75.0 & & \\
0.20 & 0.0375 & 8.75 & 110 & & \\
0.20 & 0 & 8.80 & 272 & 3885 & 7731 \\
\hline
\end{tabular}

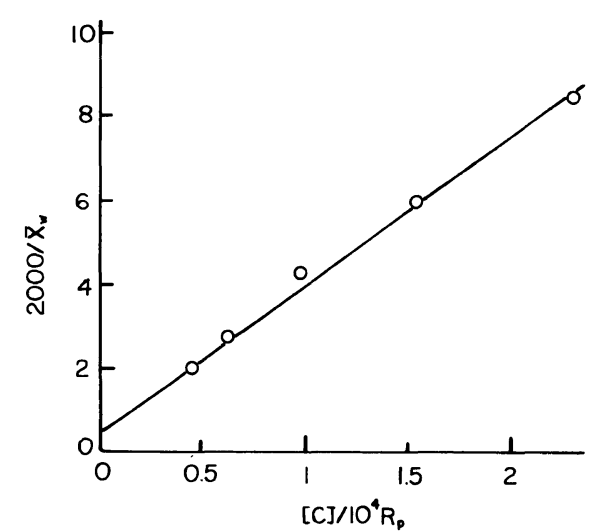

Figure 4. Analysis of the kinetic data obtained when $f_{1}=0.27$ using eq 19 .

(Table II) and a value of $C_{22: 22}=1.0 \times$ $10^{-5}$ (ref 13) into eqs 8 and 19. The former value is in good agreement with $3.28 \times 10^{-7}$ obtained previously. ${ }^{14}$ The later value is in good agreement with 72.9 which is calculated from $k_{t}=3.40 \times 10^{7}$ and $k_{22}=683 .{ }^{15}$ In the copolymerization, $2 f k_{\mathrm{d}}$ is found to be $3.50 \times 10^{-7}$ from the slope of the line in Figure 4. This value is also in good agreement with both the above values obtained in the homopolymerizations. Accordingly, the initiation rate may be invariant when $[\mathrm{C}]=$ constant. Here, an average value as $2 f k_{\mathrm{d}}=$ $3.43 \times 10^{-7}$ among the above values are used. From the intercept of the line in Figure 4, $C_{11: 11}$ and $\left(r_{1} C_{12: 11}+r_{2} C_{21: 22}\right)$ are found to both the above values obtained in the homopolymerizations. Accordingly, the initiation rate may be invariant when $[\mathrm{C}]=$ constant. Here, an average value as $2 f k_{\mathrm{d}}=$ $3.43 \times 10^{-7}$ among the above values is used. From the intercept of the line in Figure 4, $C_{11: 11}$ and $\left(r_{1} C_{12: 11}+r_{2} C_{21: 22}\right)$ are found to be 0.07 and 0.02 , respectively, where the data when $\left[\mathrm{M}_{1}\right]=1.491$ in Table II and $C_{22: 22}=1.0 \times 10^{-5}$ are used.

Polymerization rate in homopolymerization of $\alpha \mathrm{MSt}$ was so slow that a valid value of $k_{t} / k_{11}^{2}$ could not be obtaind from the data on the homopolymerization. Here, such a 
value is estimated by eq 22 of which eq 8 is rewritten.

$$
U=\left(r_{1} k_{t}^{1 / 2} / k_{11}\right)\left(\left[\mathrm{M}_{1}\right] /\left[\mathrm{M}_{2}\right]\right)
$$

where the value of $U$ is calculated as:

$$
U=\frac{\left(2 f k_{\mathrm{d}}\right)^{1 / 2}\left(1-K_{\mathrm{p}}\right)\left(r_{1}-K_{\mathrm{p}}\right)\left(r_{1}\left[\mathrm{M}_{1}\right]^{2}+2\left[\mathrm{M}_{1}\right]\left[\mathrm{M}_{2}\right]+r_{2}\left[\mathrm{M}_{2}\right]^{2}\right)}{\left(\eta / \eta_{2}\right)^{1 / 2} R_{\mathrm{p}}\left[\mathrm{M}_{2}\right]}-\frac{r_{2} k_{t}{ }^{1 / 2}}{k_{22}}
$$

Table III. Kinetic data on the modification of polymerization rate

\begin{tabular}{ccccc}
\multicolumn{5}{c}{ as $\left[R_{\mathrm{p}} /\left(1-K_{\mathrm{p}}\right)\right]\left[\eta / \eta_{2}\right]^{1 / 2}$ a } \\
\hline$\left[\mathrm{M}_{1}\right]$ & {$\left[\mathrm{M}_{2}\right]$} & $\eta / \eta_{2}$ & $10^{4} K_{\mathrm{p}}$ & $\begin{array}{c}10^{6}\left[R_{\mathrm{p}} /\left(1-K_{\mathrm{p}}\right)\right] \\
{\left[\eta / \eta_{2}\right]^{1 / 2}}\end{array}$ \\
\hline 0 & 8.80 & 1 & 0 & 272 \\
0.0375 & 8.75 & 1.001 & 0.038 & 110 \\
0.0740 & 8.70 & 1.006 & 0.149 & 74.8 \\
0.149 & 8.62 & 1.013 & 0.598 & 47.2 \\
0.373 & 8.35 & 1.032 & 3.60 & 25.6 \\
0.746 & 7.89 & 1.058 & 14.8 & 12.8 \\
1.491 & 7.00 & 1.100 & 55.8 & 8.63 \\
2.24 & 6.09 & 1.140 & 129 & 8.27 \\
2.98 & 5.20 & 1.190 & 241 & 3.76 \\
3.39 & 4.47 & 1.280 & 357 & 2.21 \\
5.97 & 1.59 & 1.380 & 1920 & 1.15 \\
\hline
\end{tabular}

a $[C]=0.20 . \quad K_{\mathrm{p}}=$ calculated when $r_{1}=0.48, r_{2}=0.47$, and $K_{11}=5.0$.

On the assumption that $k_{t} \eta=$ constant, ${ }^{4}$ this equation is modified. The ratio as $\left(\eta / \eta_{2}\right)$ is shown in Table III. The slope of the line in Figure 5 gives $k_{t}^{1 / 2} / k_{11}=2300$. On the assumption that $k_{t}$ is invariable, $k_{11}$ is found to be 2.5 , using $k_{t}=3.28 \times 10^{7}$. This assumption may be accepted, because eq 8 is applicable to all the data shown in Table III (Fiure 6).

In the preceding paper, ${ }^{4}$ the termination rate in copolymerization of DMA and MMA was explained in view of the hydrodynamic properties of the polymers. These properties have strong effect on the termination rate, because the hydrodynamic properties of polyDMA differ markedly from those of polyMMA. However, those of poly $\alpha$ MSt are approximated to those of polyMMA, since the former is similar to those of polystyrene ${ }^{13}$ approximated to the later. ${ }^{15,16}$ These approximations are consistent with the assump-

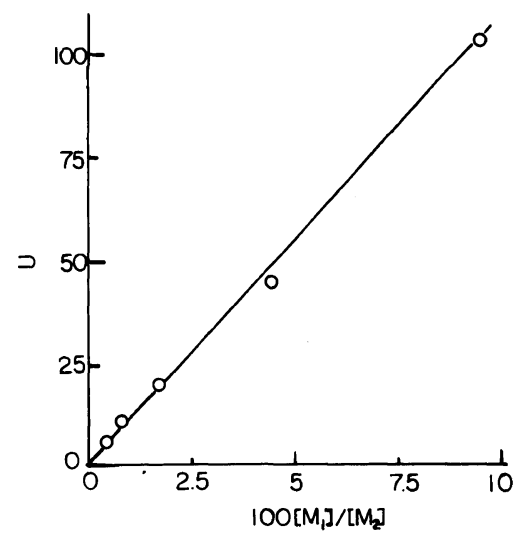

Figure 5. Estimation of $k_{2} / K_{11}{ }^{2}$.

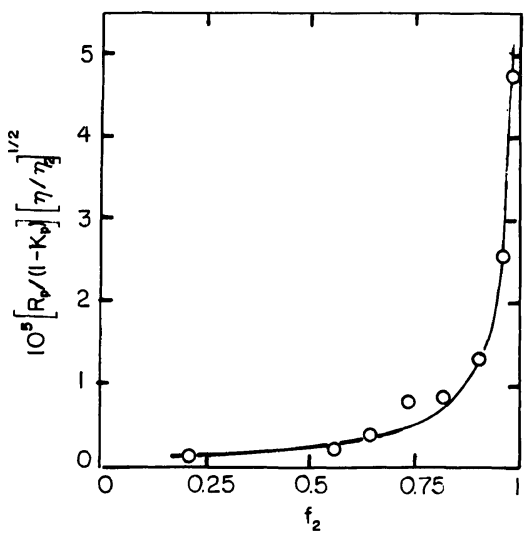

Figure 6. Relationship between polymerization rate and monomer feed composition $(\mathrm{O}$, experimental; calculated when $r_{1}=0.48, r_{2}=0.47, K_{11}=5.0, k_{22}=683$, and $k_{t}=3.28 \times 10^{7}$ ).

tion that $k_{t}$ is invariable.

Application of Russo et al.'s treatment of the present data gave $\delta_{\mathrm{BA}} / \delta_{\mathrm{A}}=-0.54$ and $\left(k_{t 21: 21} / k_{t 11: 11}\right)=0.084$ (using their terminology). A negative value is physically unrealistic. Further, although these relative values could be obtained by the least square 
method, $\delta_{\mathrm{A}}$ did not converge to the most probable value. Especially, $\left[\mathrm{M}_{1}\right]<1$, the Russo model has completely no effect. It is concluded that the Russo model cannot describe the present copolymerization nor the copolymerization between DMA and MMA.

Fukuda et $a l^{17}$ showed that the termination rate constant in the copolymerization between styrene and MMA is close to the composition average of the termination rate constants of homopolymerizations or $\phi$ is close to unity. The present result is consistent with the Fukuda et al. result. Following their treatment, $k_{11}$ and $k_{22}$ are written as (using their terminology):

$$
\begin{aligned}
& k_{11}=k_{111}\left(r_{1} f_{1}+f_{2}\right) /\left(r_{1} f_{1}+f_{2} / s_{1}\right) \\
& k_{22}=k_{222}\left(r_{2} f_{2}+f_{1}\right) /\left(r_{2} f_{2}+f_{1} / s_{2}\right)
\end{aligned}
$$

Along eq 23, the present data yield $s_{1}=1.0$ and $s_{2}=1.0$. In the copolymerization of styrene and MMA, $s_{1}=0.30$ and $s_{2}=0.53$ were obtained. If their treatment is realistic, the difference between $s_{\alpha \mathrm{MSt} \text { MMA }}$ and $s_{\text {styrene:MMA }}$ must be explained by only a difference between hydrogen and methyl group on $\alpha$ carbon. This is quite interesting and will be discussed in the near future following more experimental work.

\section{NOMENCLATURE}

$\left[\mathrm{M}_{i}\right]=$ concentration of monomer $\mathbf{M}_{i}$

$f_{i}=\left[\mathbf{M}_{i}\right] /\left(\left[\mathbf{M}_{1}\right]+\left[\mathbf{M}_{2}\right]\right)$

$F_{i}=\mathrm{d}\left[\mathrm{M}_{i}\right] /\left(\mathrm{d}\left[\mathrm{M}_{1}\right]+\mathrm{d}\left[\mathrm{M}_{2}\right]\right)$

$k_{i j}=$ propagation rate constant of radical $\sim \mathbf{M}_{i}$ to $\mathbf{M}_{j}$

$k_{i j}=$ depropagation rate constant of radical $\sim \mathbf{M}_{i} \mathbf{M}_{j}{ }^{\circ}$

$k_{t}=$ termination rate constant

$k_{t i j}=$ termination rate constant between $\sim \mathbf{M}_{i}$ and $\sim \mathbf{M}_{j}{ }^{\circ}$

$k_{r i j}=$ transfer rate constant of $\sim \mathrm{M}_{i}$ to $\mathrm{M}_{j}$

$C_{i j: \mathrm{ss}}=k_{\text {rij }} / k_{\mathrm{ss}}$

$r_{i}=k_{i i} / k_{i j}$

$K_{i j}=k_{i j} / k_{i j}$
$[\mathrm{N}]=$ total concentration of polymer radicals

$\left[\mathrm{N}_{n}{ }^{i}\right]=$ concentration of $\sim \mathrm{M}_{i}{ }^{*}$ with degree of polymerization $n$

$R_{\mathrm{p}}=$ polymerization rate

$[\mathrm{C}]=$ initiator concentration

$f=$ initiator efficiency

$k_{\mathrm{d}}=$ decomposition rate constant of initiator

$X_{n}=$ number-average degree of polymerization

$X_{w}=$ weight-average degree of polymerization

$\eta=$ solvent viscosity of copolymerization solution

$\eta_{i}=$ solvent viscosity of homopolymerization solution of $\mathbf{M}_{i}$

\section{REFERENCES}

1. C. Walling, J. Am. Chem. Soc., 71, 1830 (1949).

2. S. S. M. Chinag and A. Rudin, J. Macromol. Sci., Chem., A9, 237 (1975).

3. S. S. M. Chinag and A. Rudin, J. Polym. Sci., Polym. Chem. Ed., 12, 2235 (1974).

4. K. Ito and K. F. O'Driscoll, J. Polym. Sci., Polym. Chem. Ed., 17, 3913 (1979).

5. E. Arlmann, J. Polym. Sci., 17, 375 (1955).

6. K. Ito, J. Polym. Sci., A-1, 8, 2819 (1970); 9, 867 (1971).

7. G. Bonta, B. M. Gallo, and S. Russo, J. Chem. Soc., Faraday Trans. I, 71, 1727 (1975): the papers cited in this ref.

8. A. D. Jenkins and B. H. Mustafa, J. Polym. Sci., Polym. Lett. Ed., 19, 1 (1981).

9. S. G. Cohen and C. H. Wang, J. Am. Chem. Soc., 77, 2457 (1955).

10. P. Wittmer, Makromol. Chem., 103, 188 (1967).

11.. P. W. Tidwell and G. A. Mortimer, J. Polym. Sci., A, 3, 369 (1965).

12. Kh. S. Bagdasa'yan, "Theory of Free-Radical Polymerization," Asakurashoten for Japanese Translation, Tokyo 1964: Israel Scientific Translations Jerusalem for English Translation, 1968.

13. J. Brandrup and E. H. Immergut, Ed., "Polymer Handbook," John Wiley and Sons, Inc., New York, N. Y., 1975.

14. K. Ito, J. Polym. Sci., Polym. Chem. Ed., 16, 2725 (1978).

15. H. K. Mahabadi and K. F. O'Driscoll, J. Macromol. Sci., Chem., A11, 967 (1977).

16. H. K. Mahabadi and K. F. O'Driscoll, J. Polym. Sci., Polym. Chem. Ed., 15, 283 (1977).

17. T. Fukuda, Y.-D. Ma, and H. Inagaki, Macromolecules, 18, 17 (1985). 